\title{
ENUMERAÇÃO DE MICRORGANISMOS PSICROTRÓFICOS E TERMODÚRICOS PSICROTROFICOS DE LEITE: COMPARAÇÃO DE METODOLOGIAS
}

\section{Psychrotrophic and thermoduric psychrotrophic microorganisms enumeration in milk: comparison of methods}

\author{
Vanerli Beloti ${ }^{1}$, José Carlos Ribeiro Júnior ${ }^{{ }^{*}}$, Ronaldo Tamanini ${ }^{1}$, \\ João Paulo Andrade de Araújo ${ }^{2}$, Alberto Koji Yamadal ${ }^{1}$ Nayara da Silva Antônio ${ }^{I}$
}

\begin{abstract}
RESUMO
O objetivo do presente trabalho foi avaliar se o binômio temperatura/tempo de $21^{\circ} \mathrm{C}$ por 25 horas, já validado para enumeração de psicrotróficos em leite, apresenta viabilidade para enumeração de termodúricos psicrotróficos, comparando as contagens dos psicrotróficos e dos termodúricos psicrotróficos obtidas em cada binômio de tempo e temperatura de incubação. Foram avaliadas 28 amostras de leite cru refrigerado coletadas em tanques de caminhões transportadores na plataforma de recepção de um laticínio no norte do Paraná. Foram enumerados psicrotróficos e termodúricos psicrotróficos à $7{ }^{\circ} \mathrm{C}$ por 10 dias e a $21^{\circ} \mathrm{C}$ por 25 horas. Para os psicrotróficos, foi observado que não houve diferença significativa das contagens comparando os dois métodos de incubação $(\mathrm{p}=0,46)$, o coeficiente de correlação entre os métodos foi de 0,90 e a regressão linear considerada satisfatória. Para os termodúricos psicrotróficos, também não foi observada diferença significativa $(\mathrm{p}=0,17)$ nas contagens, porém, o coeficiente de correlação entre os dois métodos foi de 0,69 e a regressão linear insatisfatória. Foi observada também maior homogeneidade na distribuição dos resultados das contagens de psicrotróficos em relação aos termodúricos psicrotróficos. Os resultados demonstram que a enumeração de microrganismos termodúricos psicrotróficos pela metodologia mais rápida não é adequada, uma vez que o coeficiente de correlação e a regressão linear dos métodos são baixos.
\end{abstract}

Palavras-chave: bactérias termoresistentes; metodologia; termotolerantes; pasteurização.

1 Universidade Estadual de Londrina (UEL), Rodovia Celso Garcia Cid, PR-445, km 380, Campus Universitário, Caixa Postal 10. 011, CEP 86057-970, Londrina, Paraná, Brasil. Email: lipoa.uel@ gmail.com

2 Universidade Norte do Paraná (UNOPAR), Londrina, Paraná, Brasil.

* Autor para correspondência. 


\begin{abstract}
The aim of the present study was to evaluate whether the binomial temperature/ time of $21^{\circ} \mathrm{C}$ for 25 hours, already validated for enumeration of psychrotrophics in milk, presents viability for enumeration of thermoduric psychrotrophic, comparing counts of psychrotrophic and psychrotrophic thermoduric obtained from each binomial of time and temperature of incubation. Twenty-eight refrigerated raw milk samples collected in tank trucks in the reception platform of dairy industries in the northern of Paraná were evaluated. Psychrotrophic and thermoduric psychrotrophic were enumerated at $7{ }^{\circ} \mathrm{C}$ for 10 days and at $21^{\circ} \mathrm{C}$ for 25 hours. For psychrotrophic, it was observed that there was no significant difference of the counts comparing the two methods of incubation ( $\mathrm{p}=0.46$ ), the correlation coefficient between methods was 0.90 and the linear regression considered satisfactory. For thermoduric psychrotrophic it was not observed significant difference $(\mathrm{p}=0.17)$ in the counts, however, the correlation coefficient between the two methods was 0.69 and the linear regression unsatisfactory. It was also observed greater homogeneity in the distribution of the psychrotrophic counts results towards thermoduric psychrotrophic. The results demonstrate that the enumeration of thermoduric psychrotrophic microorganisms by the faster methodology can change the result of the counts, since the coefficient of correlation and linear regression methods are low.
\end{abstract}

Keywords: temperature-resistant bacteria; methodology; thermotolerant; pasteurization.

\section{INTRODUÇÃO}

A refrigeração do leite cru, determinada pela legislação brasileira (BRASIL, 2011), reduz consideravelmente a multiplicação de microrganismos com metabolismo mesofílico, principais responsáveis pelo processo de acidificação do leite cru (SANTOS; FONSECA, 2007).

No entanto, boa parte dos microrganismos mesófilos presentes no leite cru têm a capacidade de se adaptarem ao frio, ativando vias metabólicas proteolítica e/ou lipolítica, que permitem seu crescimento e multiplicação mesmo em temperaturas de refrigeração (SANTANA et al., 2001). Esses microrganismos são conhecidos como psicrotróficos. A degradação de proteínas e gordura do leite cru, provocada pelos psicrotróficos, pode acarretar problemas tecnológicos no leite UHT, principalmente durante a vida útil e industrialmente na fabricação de derivados (TAMANINI, 2012).

Os microrganismos termodúricos, por sua vez, são aqueles capazes de resistirem à pasteurização (FRANCO, LANDGRAF, 2006). No leite, esses microrganismos também podem ser psicrotróficos proteolíticos e/ou lipolíticos, deteriorando o leite pasteurizado (RIBEIRO JÚNIOR et al., 2014). Apesar disso, a legislação brasileira (BRASIL, 2011) não determina a enumeração desses microrganismos no leite cru, diferentemente da Nova Zelândia onde é estabelecido o padrão máximo de $1.500 \mathrm{UFC} / \mathrm{mL}$ (WHEELER, 2011) de termodúricos.

Para contagem dos microrganismos psicrotróficos no leite, a metodologia recomendada pelos principais órgãos de controle de qualidade internacionais é a semeadura em superfície de diluições seriadas do leite e incubação à $7{ }^{\circ} \mathrm{C}$ por 10 dias (FRANK; 
YOUSSEF, 2006). Como o período de incubação é longo e inviável em rotinas industriais, Oliveira; Parmelle (1976) alteraram com sucesso o binômio tempo/temperatura para que fosse possível a contagem de microrganismos psicrotróficos a $21{ }^{\circ} \mathrm{C}$ por apenas 25 horas. Essa metodologia rápida já é validada para psicrotróficos pela International Dairy $\mathrm{Fe}$ deration (IDF, 1991) com base no estudo de Oliveira; Parmelle (1976).

O objetivo do presente trabalho foi verificar se a metodologia de Oliveira; Parmelle (1976) também é eficiente para enumeração de termodúricos psicrotróficos do leite, avaliando a contagem dos psicrotróficos e dos termodúricos psicrotróficos em ambos os binômios de tempo e temperatura de incubação.

\section{MATERIAL E MÉTODOS}

Foram coletadas 28 amostras de leite cru refrigerado diretamente de caminhões transportadores na plataforma de recepção de uma usina de beneficiamento no norte do Paraná, nos meses de outubro e novembro de 2013. Cada amostra de $500 \mathrm{~mL}$ foi coletada em frasco estéril e imediatamente encaminhada sob refrigeração ao Laboratório de Inspeção de Produtos de Origem Animal (LIPOA) da Universidade Estadual de Londrina (UEL).

O leite cru foi diluído em solução salina $(0,85 \%)$ peptonada $(0,1 \%)$ para o plaqueamento em quadruplicata de cada diluição decimal por superfície em Ágar Padrão para Contagem (APC), sendo uma duplicata incubada a $7{ }^{\circ} \mathrm{C}$ por 10 dias (FRANK; YOUSSEF, 2006) e outra a $21^{\circ} \mathrm{C}$ por 25 horas (IDF, 1991).

Para enumeração dos microrganismos termodúricos psicrotróficos $5 \mathrm{~mL}$ de cada amostra de leite cru foram adicionadas a um tubo de ensaio estéril com tampa de rosca para o tratamento térmico $\left(62,8 \pm 0,5{ }^{\circ} \mathrm{C}\right)$ em banho-maria por 30 minutos, que foram contados a partir do momento em que um tubo controle com um termômetro atingiu a temperatura preconizada. Imediatamente após o tratamento térmico, os tubos foram imersos em banho de gelo até atingirem a temperatura de $10^{\circ} \mathrm{C}$ (FRANK;YOUSSEF, 2006). Procedeu-se então a diluição, plaqueamento e incubação das amostras da mesma forma que o leite cru.

Para análise estatística dos dados e elaboração do gráfico em Boxplot os resultados foram convertidos em $\log$ e foi utilizado o programa Statistica versão 7.0 (Stat Soft, OK, USA) utilizando $\alpha=5 \%$ no teste t de Student. Para elaboração dos gráficos de dispersão e cálculo do coeficiente de correlação foi utilizado programa Microsoft Excel $^{\circledR}$ versão 2010.

\section{RESULTADOS E DISCUSSÃO}

Os resultados das contagens de psicrotróficos nos diferentes tempos e temperaturas de incubação podem ser observados na Tabela 1. Pode-se observar que não houve diferença significativa para as médias das contagens $(p=0,46)$ e que o coeficiente de correlação entre os métodos de incubação é considerado satisfatório, assim como a regressão linear $\left(\mathrm{R}^{2}=0,80\right)$ (Figura 1).

Para os termodúricos psicrotróficos também não foi observada diferença significativa $(\mathrm{p}=0,17)$ comparando as contagens dos métodos de incubação (Tabela 2). Isso demonstra que o binômio temperatura/tempo não interferiu estatisticamente nas contagens pelos dois métodos para os dois grupos de microrganismos. No entanto, o coeficiente de correlação de 0,69 entre os métodos para enumeração de termodúricos psicrotróficos é considerado baixo. A regressão linear entre os métodos de incubação também foi considerada insatisfatória para os termodúricos psicrotróficos $\left(\mathrm{R}^{2}=0,47\right)$ (Figura 2).

Essa diferença também pode ser observada quanto à distribuição dos resultados, onde 
Tabela 1 - Resultados (log) da contagem de microrganismos psicrotróficos de 28 amostras de leite cru refrigerado em dois binômios de temperatura e tempo de incubação

\begin{tabular}{ccc}
\hline & \multicolumn{2}{c}{ Psicrotróficos $(\log \mathrm{UFC} / \mathrm{mL})$} \\
\cline { 2 - 3 } & $21^{\circ} \mathrm{C} / 25$ horas & $7^{\circ} \mathrm{C} / 10$ dias \\
\hline Média* & $7,07^{\mathrm{A}}$ & $7,07^{\mathrm{A}}$ \\
Máximo & 8,10 & 8,12 \\
Mínimo & 5,31 & 5,39 \\
Desvio Padrão & 0,72 & 0,68 \\
Coeficiente de correlação $(\mathrm{R})$ & & 0,90 \\
\end{tabular}

* Valores seguidos de letras iguais na mesma linha não diferem entre si no teste t de Student ao nível de 5\% de probabilidade.

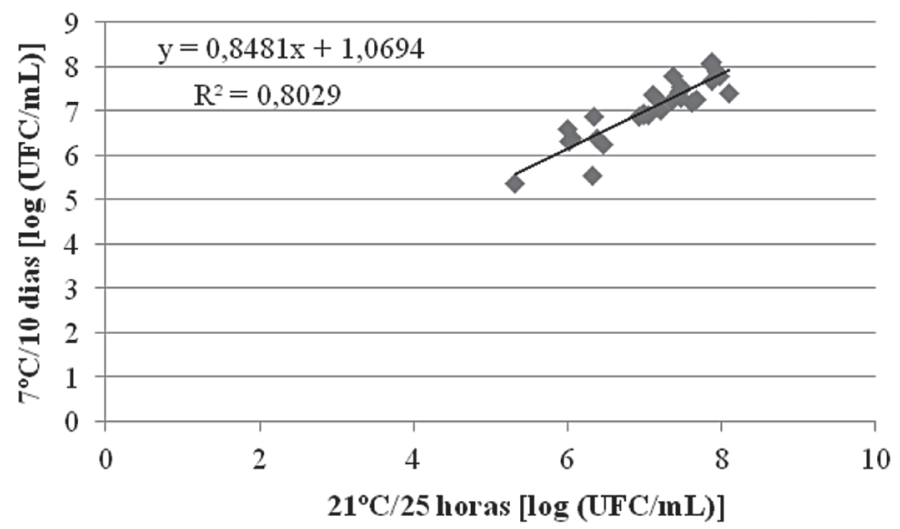

Figura 1 - Comparação da contagem de microrganismos psicrotróficos do leite cru refrigerado em dois binômios de temperatura e tempo de incubação $\left(21^{\circ} \mathrm{C} / 25\right.$ horas e $7{ }^{\circ} \mathrm{C} / 10$ dias $)$

Tabela 2 - Resultados $(\log )$ da contagem de microrganismos termodúricos psicrotróficos de 28 amostras de leite cru refrigerado em dois binômios de temperatura e tempo de incubação

\begin{tabular}{ccc}
\hline & \multicolumn{2}{c}{ Termodúricos Psicrotróficos $(\log \mathrm{UFC} / \mathrm{mL})$} \\
\cline { 2 - 3 } $21^{\circ} \mathrm{C} / 25$ horas & $7{ }^{\circ} \mathrm{C} / 10$ dias \\
\hline Média* & $3,01^{\mathrm{A}}$ & $2,89^{\mathrm{A}}$ \\
Máximo & 5,28 & 4,73 \\
Mínimo & 1,70 & 0,70 \\
Desvio Padrão & 0,83 & 0,82 \\
Coeficiente de correlação (R) & & 0,69
\end{tabular}

* Valores seguidos de letras iguais na mesma linha não diferem entre si no teste t de Student ao nível de 5\% de probabilidade. 


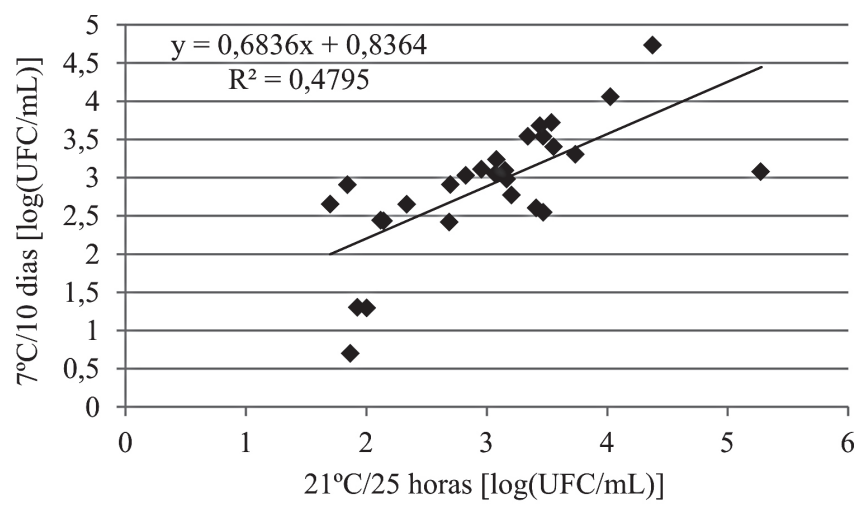

Figura 2 - Comparação da contagem de microrganismos termodúricos psicrotróficos do leite em dois binômios de temperatura e tempo de incubação $\left(21^{\circ} \mathrm{C} / 25\right.$ horas e $7{ }^{\circ} \mathrm{C} / 10$ dias $)$

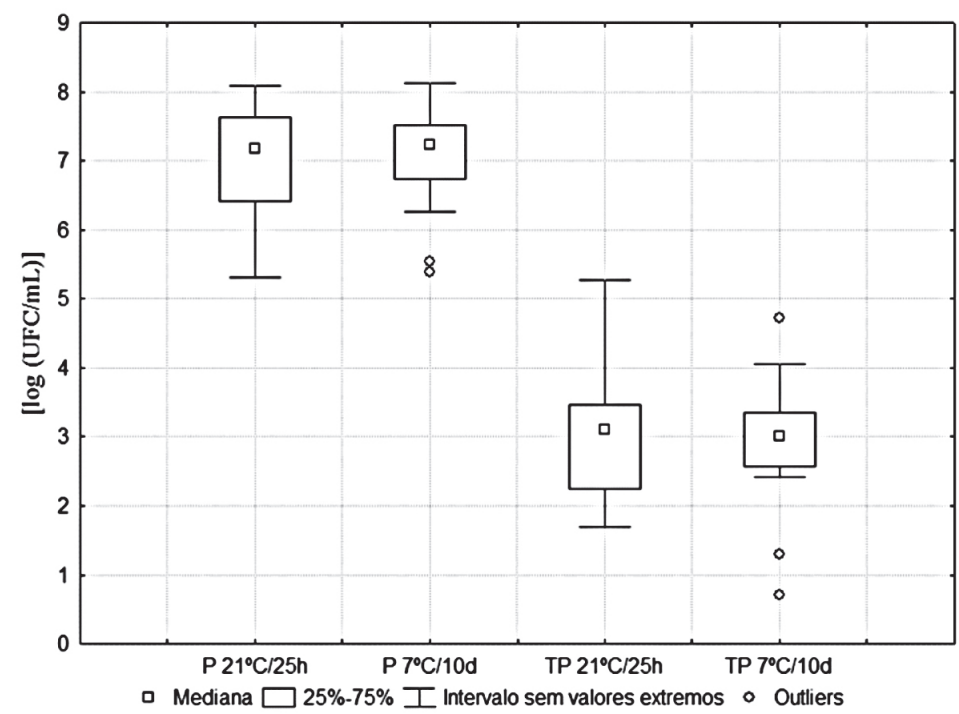

Figura 3 - Distribuição dos resultados $(\log )$ da contagem de microrganismos psicrotróficos $(\mathrm{P})$ e termodúricos psicrotróficos (TP) de 28 amostras de leite cru refrigerado em dois binômios de temperatura e tempo de incubação $\left(21^{\circ} \mathrm{C} / 25 \mathrm{~h}\right.$ e $\left.7{ }^{\circ} \mathrm{C} / 10 \mathrm{~d}\right)$

as contagens de psicrotróficos apresentaram distribuição mais homogênea na comparação dos métodos em relação aos termodúricos psicrotróficos na mesma comparação (Figura 3).

Há grande diversidade de microrganismos psicrotróficos do leite, grupo no qual já foram descritos mais de 34 gêneros de microrganismos, Gram positivos e negativos (JAY, 2008).

Os psicrotróficos termodúricos são representados pelos gêneros Arthrobacter, Microbacterium, Streptococcus, Corynebacterium, 
Clostridium e principalmente pelo gênero Bacillus spp. (COLLINS, 1981). Os que resistem à pasteurização do leite com alta taxa de sobrevivência pertencem aos gêneros Bacillus, Paenibacillus, Micrococcus e Mycobacterium e, com baixa taxa de sobrevivência alguns Enterococcus, Streptococcus e Lactobacilluse, algumas vezes, a outros gêneros Gram positivos (JAY, 2008).

Estudos preliminares demonstram que alguns microrganismos termodúricos psicrotróficos também desempenham papel fundamental na deterioração do leite pasteurizado, uma vez que resistem à pasteurização e continuam a produzir enzimas proteolíticas, podendo estar diretamente relacionados à redução da vida útil desse leite. Ribeiro Júnior et al. (2014) avaliaram 20 amostras de leite cru refrigerado na região norte do estado do Paraná e encontraram média de $3,5 \times 10^{3} \mathrm{UFC} / \mathrm{mL}$ de termodúrico spsicrotróficos. Esses mesmos autores isolaram 347 colônias puras e verificaram que 142 (40,1\%) apresentam halos de proteólise em ágar leite suplementado com solução de leite em pó desnatado.

Em suma, binômio temperatura/tempo sugerido por Oliveira; Parmelle (1976) para psicrotróficos não apresenta resultados satisfatórios para enumeração de microrganismos termodúricos psicrotróficos em leite. Isso pode estar relacionado às diferenças metabólicas e enzimáticas desses microrganismos.

\section{CONCLUSÕES}

O baixo coeficiente de correlação dos binômios de temperatura e tempo de incubação dos termodúricos psicrotróficos a $21{ }^{\circ} \mathrm{C}$ por 25 horas em relação ao método tradicional de $7{ }^{\circ} \mathrm{C}$ por 10 dias sugere que a metodologia mais rápida não é eficiente para esses microrganismos em comparação ao mesmo método para enumeração de psicrotróficos.

\section{REFERÊNCIAS}

BRASIL. Ministério da Agricultura, Pecuária e Abastecimento. Departamento de Inspeção de Produtos de Origem Animal. Instrução Normativa $n^{\circ}$ 62, de 26 de agosto de 2003. Oficializa os métodos analíticos oficiais para análises microbiológicas para controle de produtos de origem animal e água. Diário Oficial da República Federativa do Brasil, Brasília, 18 set. 2003. Seção 1, p. 14.

COLLINS, E. B. Heat resistant psychrotrophicmicroorganisms. Journal of Dairy Science, v. 64, n. 1, p. 157-160, 1981.

FRANCO, B. D. G. M.; LANDGRAF, M. Microbiologia dos Alimentos. $2^{\mathrm{a}}$ ed. Atheneu: São Paulo, 2003.182 p.

FRANK, J. F.; YOUSEF, A. E. Test for groups of microrganisms. In: WEHR, H. M.; FRANK, J. K (Eds.) Standard Methods for the Examination of Dairy Products, $17^{\text {th }}$ ed. Washington: American Public Health Association, 2004. Chapter 8, p. 239-242.

INTERNATIONAL DAIRY FEDERATION (IDF). Estimation of numbers of psychrotrophic microorganisms: rapid colony count technique $25 \mathrm{hs}$ at $21{ }^{\circ} \mathrm{C}$. Nottingham, 1991.

JAY, J. M. Microbiologia de Alimentos. $6^{\mathrm{a}}$ ed. Porto Alegre: Artmed, 2008. 711p.

OLIVEIRA, J. S.; PARMELEE, C. E. Rapid enumeration of psychrotrofic bacteria in raw and pasteurized milk. Journal of Milk and Food Technology, v. 39, n. 4, p. 269-272, 1976.

RIBEIRO JÚNIOR, J. C. et al. Microorganismos termodúricos psicrotróficos com 
atividade proteolítica em leite cru refrigerado. In: SUL LEITE - SIMPÓSIO SOBRE SUSTENTABILIDADE DA PECUÁRIA LEITEIRA NA REGIÃO SUL DO BRASIL, 6., 2014, Maringá. Anais... Maringá: UEM, 2014. 1 CD-ROM.

SANTANA, E. H. W. et al. Contaminação do leite em diferentes pontos do processo de produção: I. Microrganismos aeróbios mesófilos e psicrotróficos. Semina: Ciências Agrárias, v. 22, n. 2, p. 143-154, 2001.

SANTOS, M. V.; FONSECA, L. F. L. Qualidade do leite e controle de mastite. São Paulo: Lemos Editorial, 2007. 288 p.
TAMANINI, R. Controle de qualidade do leite UHT. 2012. 285 p. Tese (Doutorado em Ciência Animal) - Universidade Estadual de Londrina, Londrina, 2012.

WHEELER, J. The causes of and solutions to bacterial downgrades in milk on Australian dairy farms with reference to the approach used in New Zealand. In: COUNTDOWN SYMPOSIUM, 2011, Melbourne - Austrália. Proceedings... Melbourne: University of Melborne, Dairy Australia, 2011. Disponível em: <http://www.primarylogic.com.au/wpcontent/uploads/2013/01/Mastitis-symposium2011-text-FOR-WEB.pdf\# page=13>. Acesso em: 28 out. 2014. 